\title{
The unusual state of the cumulus oophorus and of sperm behaviour within it, in the musk shrew, Suncus murinus
}

\author{
J. M. Bedford ${ }^{1}$, T. Mori ${ }^{2}$ and S. Oda ${ }^{3}$ \\ ${ }^{1}$ Depts of Obstetrics and Gynecology and Cell Biology and Anatomy, Cornell University Medical College, \\ New York, NY 10021, USA; ${ }^{2}$ Zoological Laboratory, Faculty of Agriculture, Kyushu University, \\ Fukuoka 812, Japan; and ${ }^{3}$ Laboratory of Animal Management, School of Agricultural Sciences, \\ Nagoya University, Nagoya 464, Japan
}

In the musk shrew, Suncus murinus, the behaviour of the cumulus-egg complex and its interaction with spermatozoa were unusual in several respects. The cumulus oophorus was ovulated about $15.5 \mathrm{~h}$ after mating or treatment with hCG as a hyaluronidase-insensitive matrix-free ball of cells which remained for relatively long periods of about $14 \mathrm{~h}$ around fertilized, and for about $24 \mathrm{~h}$ around unfertilized eggs. As a probable function of the small number of up to about 10 or 20 spermatozoa that generally reached the oviduct ampulla from isthmic crypts, there was often a delay of up to $10 \mathrm{~h}$ after ovulation before most eggs were penetrated. Soon after ovulation, however, the corona radiata retreated progressively from the zona pellucida, creating a closed perizonal space within the cumulus oophorus. Usually, most spermatozoa that did reach the ampulla were found within a cumulus and generally within that perizonal space. However, whereas the acrosome was intact among the few free ampullary spermatozoa, and in those adhering to the zona of cumulus-free eggs after delayed mating, all spermatozoa seen moving within the cumulus or adhering to the zona of unfertilized eggs had shed the giant acrosome. In accord with current observations in other shrews, the cumulus in Suncus may therefore function not only to sequester spermatozoa, but also as an essential mediator of fertilization - probably by inducing the acrosome reaction. In the absence of the acrosomal carapace that expresses the zona receptors in most mammals, fertilizing Suncus spermatozoa could use an unusual array of barbs on the exposed perforatorium to attach to the zona pellucida.

\section{Introduction}

The Insectivora, comprising shrews, moles and hedgehogs, display a number of primitive characteristics and are considered to represent existing links to the progenitors of eutherian mammals (Yates, 1984). Therefore, it is interesting that in the few crocidurine and soricine shrews studied, the form and behaviour of their gametes differ in several respects from the corresponding features seen generally in higher mammals. An early report on the short-tailed shrew Blarina brevicauda (Pearson, 1944) indicated that its spermatozoa invade and may possibly sometimes fertilize within ovarian follicles (as in the Madagascar hedgehog: Strauss, 1952). Among the unusual features in other shrews are: (i) hypertrophic development of the crocidurine acrosome, (ii) small numbers of spermatozoa inseminated, (iii) crypts that come to house spermatozoa in the isthmus, in the ampulla, or in the isthmus and ampulla of the Fallopian tube, according to the genus, and (iv) a highly compact cumulus oophorus that can remain for up to $24 \mathrm{~h}$ (Suncus murinus, Crocidura russula), or soon proliferates after fertilization coincidentally with a secretion of cumulus matrix apparently stimulated by tubal factors (Cryptotis parva)

Received 6 November 1996
(Bedford et al., 1994, 1997a,b,c). After making preliminary observations on the gametes of the musk shrew, Suncus murinus (Bedford et al., 1994), we conducted a systematic analysis of the transport of spermatozoa and of eggs and embryos in its female tract (Bedford et al., 1997a), and have also studied the events of fertilization. The unusual aspects of the interactions between spermatozoa and eggs of Suncus are described, with particular focus on the behaviour of the cumulus oophorus, the state of spermatozoa within it, and its role in fertilization.

\section{Materials and Methods}

The animals were either born and reared at Kyushu University, or came directly from stocks of the Laboratory of Animal Management, School of Agricultural Sciences, Nagoya University. Their husbandry and the techniques involved in mating and collection of cumulus-oocyte complexes are described by Dryden (1969), and in a companion paper (Bedford et al., 1997a).

Briefly, ovulation was induced by mating or by an i.p. injection of hCG. In addition, since female receptivity is not confined to a limited time window in Suncus, five females were permitted to copulate at different times soon after 
hCG-induced ovulation, in an attempt to observe the interaction of spermatozoa with eggs after natural loss of the cumulus oophorus. Since the cumulus is not lost from unfertilized eggs until about $24 \mathrm{~h}$ after ovulation (Bedford et al., 1994; and see below), natural mating occurred between 18 and $38 \mathrm{~h}$ after a prior injection of hCG, and so 3-23 h after ovulation.

At various times after ovulation, oviducts were placed in Dulbecco's modified Eagle's medium (DMEM) plus BSA (3 mg $\mathrm{ml}^{-1}$ ) and dissected free of the mesosalpinx and ovarian bursa before mounting on a wax-spot slide. Initially, the oviduct was slightly compressed for direct visual examination by transillumination using differential interference contrast (DIC) optics. Particular attention was paid to the state of the cumulus in situ, and to the acrosomal status of spermatozoa moving within it, or free within the ampulla. Oviducts were then easily recovered from the wax spot slide and, according to the time after mating or hCG, cumulus-invested oocytes or cumulus-free oocytes were extruded from the ampullary region with fine forceps. The ampullary content from mated animals was scanned systematically for free spermatozoa and their acrosomal status, and the cumuli or eggs were remounted beneath a cover glass supported by wax spots, for further study. With slight compression it was possible to distinguish all the spermatozoa associated with the cumulus, as well as their motility and their acrosome status. For assessment of fertilization, recovered eggs were freed of cumulus with fine needles, and then anchored again beneath a cover glass on wax-spot slides. After examination with phase contrast or DIC optics, the naked eggs were fixed in acetic alcohol (I:3) and then lightly stained with $0.75 \%(\mathrm{w} / \mathrm{v})$ lacmoid in $45 \%(\mathrm{v} / \mathrm{v})$ acetic acid and assessed in a phase contrast microscope.

The intact cumulus oophorus was also studied histologically in examples recovered about $15.5 \mathrm{~h}$ after treatment with hCG at the time of ovulation, and in unfertilized and fertilized eggs recovered $6-7 \mathrm{~h}$ after ovulation, i.e. about $21-22 \mathrm{~h}$ after treatment with hCG or mating, respectively. For this purpose, the cumulus was immediately fixed in $3 \%(\mathrm{v} / \mathrm{v})$ glutaraldehyde in $0.2 \mathrm{~mol}$ sodium cacodylate $1^{-1}$ buffer $\left(4^{\circ} \mathrm{C}, \mathrm{pH} 7.4\right)$ and embedded in Kulzer Technovit 7100 methacrylate resin. Thick sections were stained with $0.5 \%(\mathrm{w} / \mathrm{v})$ toluidine blue.

Further experiments were aimed at in vitro fertilization, using epididymal, vaginal (ejaculated) or isthmic spermatozoa. For this, spermatozoa were released from the cauda epididymidis to a concentration of $0.5 \times 10^{6} \mathrm{ml}^{-1}$ into wells (Nunclon: Intermed) containing DMEM + BSA, under mineral oil at $37^{\circ} \mathrm{C}$. Ejaculated spermatozoa were prepared similarly on recovery from the anterior vagina about $30 \mathrm{~min}$ after coitus. Isthmic spermatozoa were gently stripped with fine forceps directly into this medium under mineral oil, some $14-20 \mathrm{~h}$ after coitus. One to three hours later, cumulus-invested oocytes and oocytes freed of cumulus were incubated with the respective sperm populations for up to $24 \mathrm{~h}$.

\section{Results}

\section{The cumulus oophorus}

The preovulatory follicle had a very small antrum, and the cumulus oophorus was ovulated as a dense sphere of cells essentially free of intercellular matrix. However, a closed space soon developed between the zona pellucida and the surrounding corona radiata. Sections showed the beginnings of a perizonal space already immediately after ovulation, at which time the inner corona radiata had a distinctly radial configuration (Fig. 1a). Slight shrinkage disclosed myriad persistent intercellular connections that in a previous transmission electron microscope study resembled gap junctions (Bedford et al., 1994). The perizonal space enlarged during the next few hours (Fig. Ib), even when the egg was unfertilized, creating a halo effect in whole mount preparations (Fig. Ic). The corona radiata later lost its radial configuration (Fig. Ib), but the intercellular junctions remained as the cumulus became progressively more distorted in situ before its loss.

The cumulus generally remained around penetrated eggs at 24-28 h after coitus, i.e. about $13 \mathrm{~h}$ after ovulation (Fig. 2a), but $\geq 30 \mathrm{~h}$ after mating they were naked (Fig. 2c). In the absence of spermatozoa, the cumulus remained around all eggs collected from four females at $34 \mathrm{~h}$ after hCG, and in two of six such females $40-43 \mathrm{~h}$ after hCG, but not later in any recovered from ten hCG-injected females. These results are consistent with preliminary observations (Bedford et al., 1994) that the cumulus is lost after about 12-14 h from fertilized eggs, but remains for about $24 \mathrm{~h}$ around unfertilized tubal eggs.

\section{Relationship of spermatozoa with cumulus and egg}

The interaction of Suncus gametes in the ampulla was notable for the very few spermatozoa there at any time, and for the fact that all (mostly motile) spermatozoa seen within the cumulus no longer had an acrosome. Generally no more than one or two spermatozoa had reached most ampullae by $2-4 \mathrm{~h}$ after ovulation, at which time only $13.8 \%$ of eggs had been penetrated (Table 1). Although progressively more were penetrated over the next few hours, the number of spermatozoa within the cumulus usually remained very low, often with even fewer free spermatozoa in the ampulla. In addition to four oviducts in which 29-87 spermatozoa reached the ampulla in the absence of ovulation (Beford et al., 1997a), in two atypical cases, 21 and 61 free spermatozoa were recovered with eggs at $21.5 \mathrm{~h}$ and $27 \mathrm{~h}$ after coitus, respectively. Otherwise, the number of free spermatozoa was low; and approximately half of the ampullae contained no free spermatozoa. There was a gradual modest buildup within the cumulus; the maximum was 16 spermatozoa in one recovered $27.5 \mathrm{~h}$ after coitus. In general, however, only a few spermatozoa remained within a cumulus until its loss about $14 \mathrm{~h}$ after ovulation.

Since the giant acrosome of Suncus is seen very easily, its presence or absence could be assessed accurately in free spermatozoa within the ampulla and in those within the cumulus; in the latter after slight flattening of the cumulus, in situ, or after recovery. In cumuli recovered from a total of 51 oviducts at various times between 17 and $28 \mathrm{~h}$ after coitus, the few associated spermatozoa were generally motile and upon slight flattening of the cumulus they could be seen clearly with DIC optics moving within the perizonal space (Fig. 3a). These spermatozoa were notable in three respects. Whereas the few motile free ampullary spermatozoa were intact, as were two spermatozoa at the cumulus surface, the acrosome was absent 

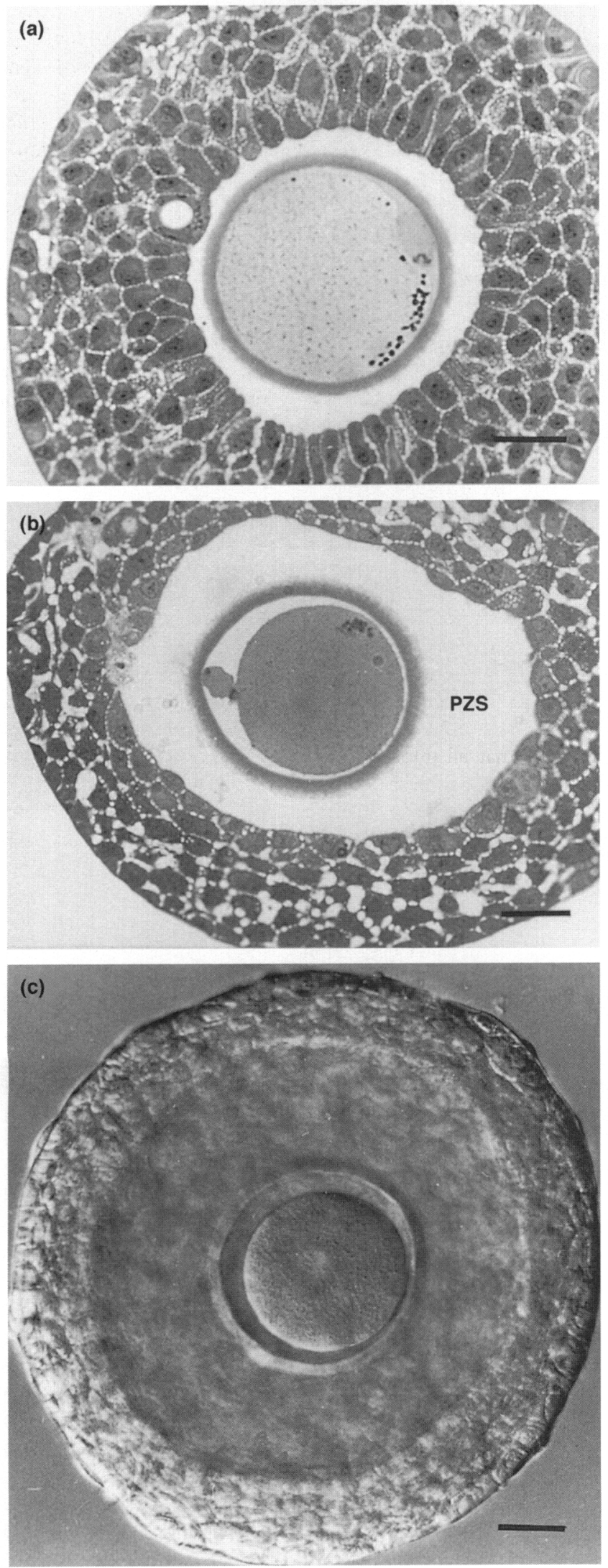

(Fig. 3b) in $100 \%$ of the 413 (about $70 \%$ motile) spermatozoa visualised within 86 cumuli at all times from 2 to $13 \mathrm{~h}$ after ovulation. In some cases its absence was further confirmed in spermatozoa released by rupture of the cumulus with needles. Second, the tails of the reacted perizonal spermatozoa often were curled, rather than straight as in intact spermatozoa. Third, reacted motile perizonal spermatozoa showed no tendency to adhere to the surface of the zona pellucida around fertilized eggs.

In that last regard, however, after routine removal of the cumulus a spermatozoon was discovered on four occasions attached to unfertilized eggs (Fig. 4a). These were notable for the obvious tenacity of that attachment, revealed by rolling the egg, and for the fact that the sperm head was adhering to the zona by the apex of the inner acrosome membrane with no remnant of the acrosome in evidence. Attachment of intact spermatozoa to the zona pellucida was observed only in two naked unfertilized eggs recovered from 'delayed' females mated, respectively, $4 \mathrm{~h}$ and $24 \mathrm{~h}$ after hCG-induced ovulation, with each unfertilized egg having three intact motile spermatozoa adhering by the acrosome to the zona surface (Fig. 4b). In one case, a spermatozoon was observed to work itself free and swim away leaving the intact acrosome stuck to the zona of the egg.

Results from delayed mating served to show also that some Suncus spermatozoa become capable of fertilization in less than $10 \mathrm{~h}$ after insemination. For example, in one female mated $7 \mathrm{~h}$ after ovulation, four of four eggs were fertilized and had reached the two-cell stage only $19 \mathrm{~h}$ after coitus. In another female mated $19.5 \mathrm{~h}$ after ovulation, four of the six eggs fertilized had pronuclei $11.5 \mathrm{~h}$ after insemination. However, there was no penetration or attachment of spermatozoa to the zona during in vitro fertilization trials with either epididymal, ejaculated, or even motile isthmic spermatozoa. Epididymal and ejaculated spermatozoa displayed very active motility for at least $5 \mathrm{~h}$ in vitro, although only a few isthmic spermatozoa did so. However, after co-incubation for 5-24 h, no eggs were penetrated by any category of spermatozoa, nor were any spermatozoa adherent to the exposed zona pellucida of unfertilized eggs.

Fig. 1. (a) Section through a cumulus oocyte complex of Suncus murinus recovered at the time of ovulation, about $15 \mathrm{~h}$ after treatment with hCG. The corona radiata displays a somewhat radial arrangement, but has started to withdraw from the zona pellucida to create the beginning of a perizonal space. The myriad connections that can be seen between the tightly apposed cumulus cells appear in the transmission electron microscope to be gap junctions. (b) Section through a cumulus-oocyte complex recovered from a mated female at $21.5 \mathrm{~h}$ after coitus. The second polar body had been extruded and, compared with that in (a), the cumulus had retracted further from the zona pellucida to form a bigger perizonal space (PZS). Although the inner radial arrangement has been lost, the cumulus cells still displayed many interconnections. Glutaraldehyde and osmium; toluidine blue. (c) Fresh cumulus-oocyte complex recovered from a mated female $22 \mathrm{~h}$ after coitus and photographed with differential interference contrast (DIC) optics. This illustrates how, when the cumulus is slightly compressed, the perizonal space creates a 'halo' effect. Scale bars represent $30 \mu \mathrm{m}$. 

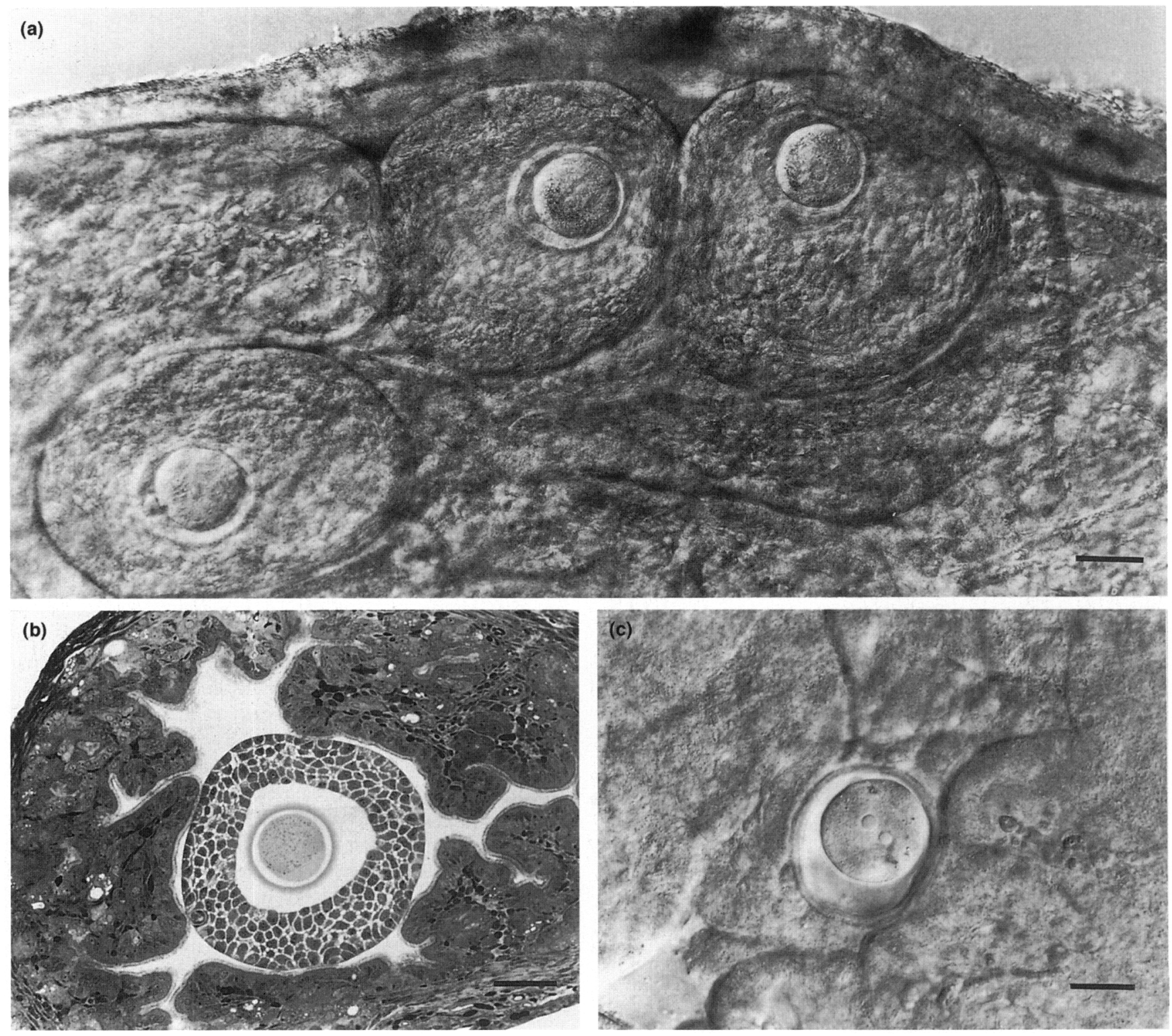

Fig. 2. (a) Three fertilized eggs of Stncus murinus with faint pronuclei within cumulus oophorus, seen in situ $26 \mathrm{~h}$ after mating. While slight compression of the ampulla has displaced two cumuli against the oviduct wall, there is a tight relationship between these and the epithelial folds in vivo. Differential interference contrast optics (DIC). Scale bar represents $62 \mu \mathrm{m}$. (b) Section through a cumulus-oocyte complex within the ampulla $22 \mathrm{~h}$ after treatment with hCG. In keeping with the unfertilized state the cumulus has a somewhat more compact appearance than that around the fertilized egg of comparable age in Fig. 1(b). This preparation also serves to illustrate the typically narrow ampullary lumen, and intimate relationship between the epithelial folds and the cumulus oophorus. Glutaraldehyde and osmium; toluidine blue. Scale bar represents $80 \mu \mathrm{m}$. (c) A fertilized pronucleate egg in the ampulla of the Fallopian tube of Suncus murinus, $30 \mathrm{~h}$ after mating. The cumulus oophorus has been shed and the space within the folds of ampullary epithelium is typically no larger than the egg. DIC. Scale bar represents 45 um

\section{Discussion}

The preliminaries to fertilization are in some ways more complex in eutherian mammals than in many invertebrates and other vertebrates. The very few spermatozoa that reach the fertilization site must have achieved capacitation, and then fertilizing spermatozoa must negotiate a way through the matrix of the cumulus oophorus before undergoing an acrosome reaction induced by the zona pellucida, often soon after ovulation. In Suncus murinus, which is a crocidurine shrew, some variants on this common eutherian theme include the late timing of fertilization linked to low numbers of spermatozoa at the site; the longevity, character, behaviour and possibly essential role of the cumulus oophorus; the occurrence of the AR within it and, as a seguitur, the way spermatozoa interact with the zona pellucida. The pattern of these variants differed in several respects also from that in the other subfamily, Soricinae, exemplified by the least shrew, Cryptotis paroa (Bedford et al., 1997c). It is clear for small muroid rodents that the spermatozoa: egg ratio in the ampulla hardly exceeds unity 
Table 1. Sperm-cumulus relationships in the ampulla of the oviduct in Suncus murinus at different times after coitus

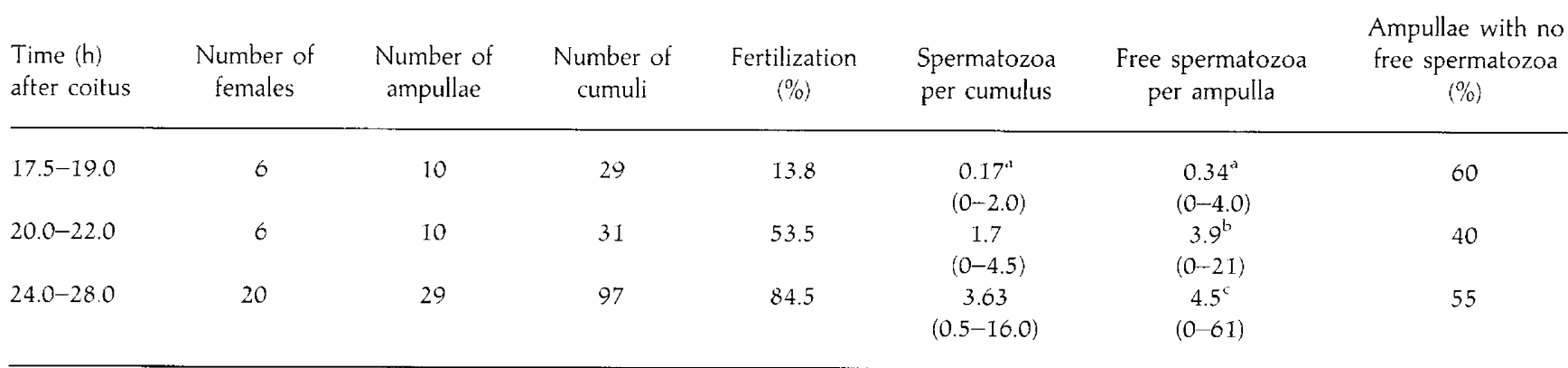

\footnotetext{
"Mean/range.

b. $1.0(0-3)$ for $80 \%$ of ampullae.

$1.7(0-12)$ for $93 \%$ of ampullae.
}
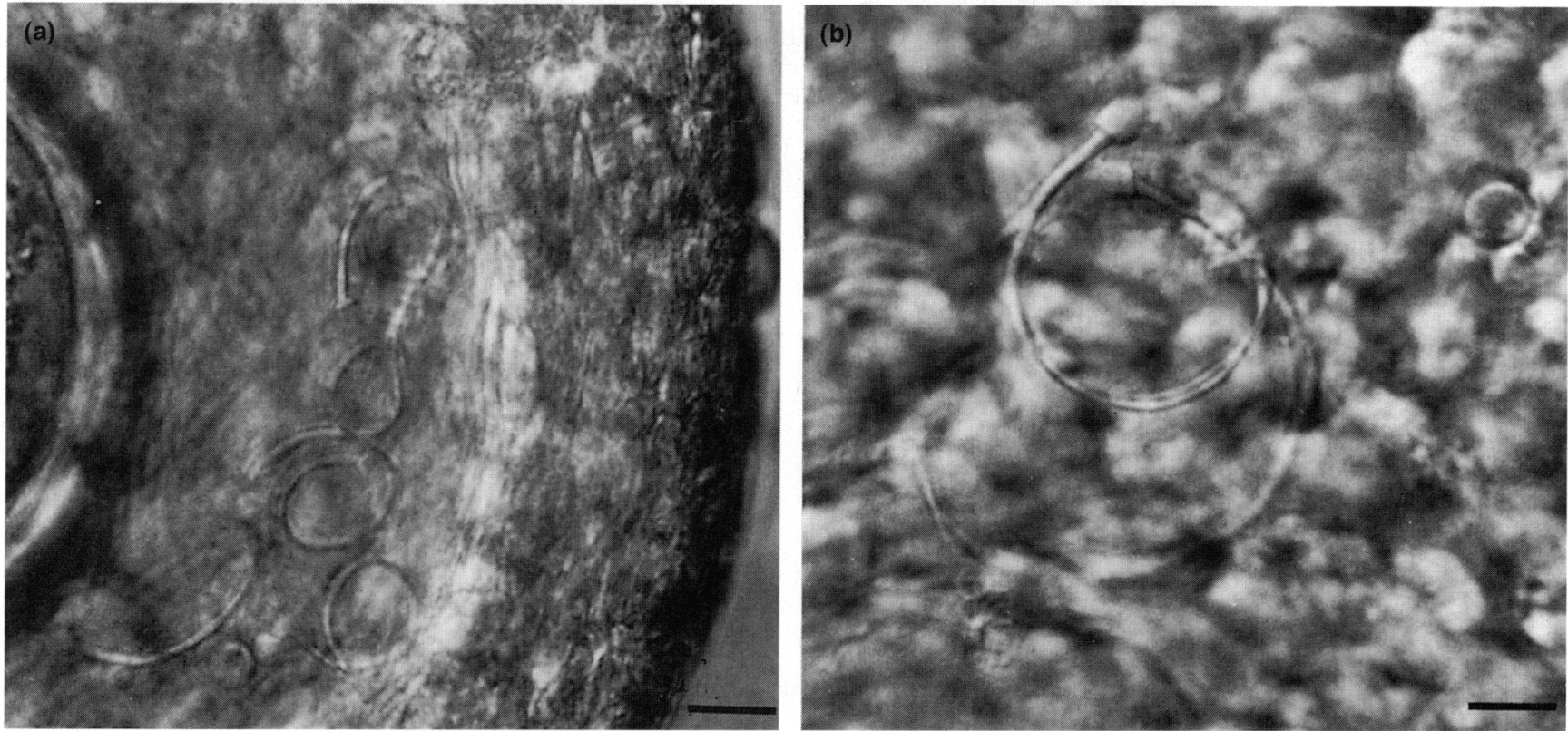

Fig. 3. (a) Segment of a cumulus recovered about $27 \mathrm{~h}$ after mating. Within the perizonal space of the compressed cumulus there are several spermatozoa whose tails often tended to curl. As illustrated in (b), the acrosome was absent in all of the several hundred such spermatozoa seen clearly within many cumuli. Differential interference contrast optics (DIC). Scale bar represents $13 \mu \mathrm{m}$. (b) Two spermatozoa within the perizonal space of a cumulus oophorus recovered about $25 \mathrm{~h}$ after mating and compressed to reveal details of their anatomy. In such cases the spermatozoa were often motile; they often had curled tails, and none had any visible remnant of the acrosome. DIC. Scale bar represents $9.5 \mu \mathrm{m}$.

as fertilization begins (Zamboni, 1972; Cummins and Yanagimachi, 1982; Shalgi and Phillips, 1988). However, the ampullary spermatozoa population may eventually reach several hundred in such rodents, whereas in Suncus it often hardly attained double figures. Although there were several hundred spermatozoa within crypts in the isthmus of the Fallopian tube then, generally no more than one or two spermatozoa were recoverable from the ampulla by about $4 \mathrm{~h}$ after ovulation, and none was retrieved then from $50 \%$ of the ampullae. Even 10-13 h after ovulation when most eggs had been fertilized, the mean number of spermatozoa recoverable from the ampulla and cumuli together was generally no more than up to about ten to twenty. An associated feature was the unusually long period before most eggs were fertilized. Delayed matings indicate that Suncus spermatozoa can fertilize within $10 \mathrm{~h}$ after insemination. Therefore the common interval of $7 \mathrm{~h}$ and more after ovulation before many eggs are fertilized in Suncus (i.e. $>20 \mathrm{~h}$ after coitus) probably reflects the scarcity of spermatozoa at the site. This natural delay seems to be at variance with the generally accepted principle that mammalian eggs are fertilized soon after ovulation. However, this delay is not typical for shrews, since fertilization occurred much earlier in the upper infundibular region of the soricine, Cryptotis parva (Bedford et al., 1997c), and similarly in another crocidurine shrew, Crocidura russula (Bedford et al., 1997b), in both of which spermatozoa are housed in crypts located within the adjacent ampulla.

It is not clear why the corona radiata should soon withdraw to create a closed perizonal space. However, regardless of the significance of this, the present observations indicate that the 

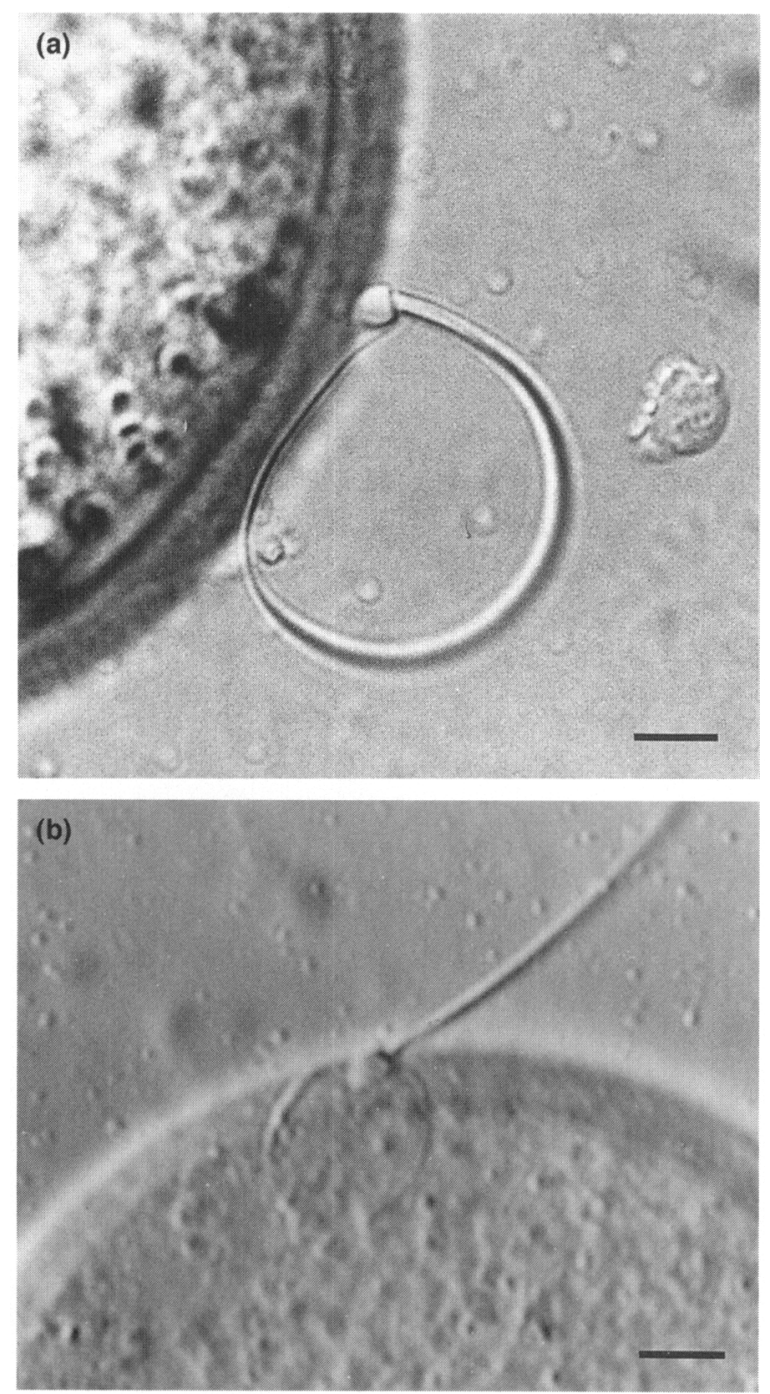

Fig. 4. (a) Unfertilized egg released from a cumulus $25 \mathrm{~h}$ after mating. The immotile spermatozoon adhering to the zona had no remnant of the acrosome. This apical attachment was tenacious since the spermatozoon could not be dislodged by vigorous rolling of the egg beneath the cover glass. Differential interference contrast optics (DIC). Scale bar represents $9.5 \mu \mathrm{m}$. (b) Spermatozoon with intact acrosome adhering to the zona pellucida of a cumulus-free egg recovered from the ampulla $12 \mathrm{~h}$ after (delayed) mating performed $41 \mathrm{~h}$ after treatment with hCG (i.e. about $25 \mathrm{~h}$ after ovulation). This egg had two other intact spermatozoa attached to its zona. Epididymal, vaginal or isthmic spermatozoa showed no such affinity for the zona when cultured with naked eggs in vitro. Printed from a colour negative on Kodak Panalure high contrast paper. DIC. Scale bar represents $10 \mu \mathrm{m}$.

cumulus plays more than one role in Suncus, and that it may be essential for fertilization - unlike that of humans and most other mammals. A subtle role for the cumulus exemplified by spermatozoa: cumulus and spermatozoa: ampullary fluid ratios in rats (Bedford and Kim, 1993) appears to be the provision of a sequestering 'trap' for the few spermatozoa that initially reach the spacious ampulla - a cumulus function that is perhaps enhanced by the expansion of this target brought by preovulatory secretion of hyaluronic acid matrix (Bedford, 1996).
In the case of Suncus, however, the modest upper oviduct segment hardly qualifies for the term 'ampulla' (swollen vessel); its narrow lumen and the cumulus are of similar size. It may be, therefore, that the cumulus in Suncus (and possibly other Insectivora) does not 'need' to expand to fulfill a spermtrapping function. However, even in its compact state the cumulus of Suncus clearly is attractive to the few spermatozoa that reach the ampulla. The distribution of spermatozoa between the ampulla and the ampullary lumen was markedly skewed; all the ampullary spermatozoa were located within the cumulus at every time period in $40-50 \%$ of the oviducts examined. When the number of spermatozoa in the ampulla was maximal about $10-13 \mathrm{~h}$ after ovulation, $86 \%$ of 29 oviducts with eggs had more spermatozoa within the cumulus than were free, and the mean ratio was about 10:1.

Although the cumulus seemed to attract the few spermatozoa reaching the ampulla, it is not clear how they penetrated the interstices of this mass, which is insensitive to hyaluronidase and to trypsin (Bedford et al., 1994). Nor has the ultrastructure of the acrosome reaction been defined, a point which is of interest in the light of the unusual stable acrosome periphery and relationship between the outer acrosome and plasma membranes (Bedford et al., 1994). At all events, regardless of its exact character, the acrosome reaction in Suncus seems to be induced by the cumulus. This was first suggested in that earlier study, and the present results support such a role for the cumulus. For although the acrosome was intact in the few motile free spermatozoa and in two spermatozoa adhering to the surface of the cumulus, it was consistently absent in all spermatozoa seen moving within or released from the cumulus. A similar situation occurs in Crocidura russula, another crocidurine, in which the more numerous active spermatozoa within the perizonal space also were devoid of the highly visible acrosome (Bedford et al., 1997b). In view of this role, it appears reasonable that the cumulus persists for an unusually long period of about $24 \mathrm{~h}$ around unfertilized crocidurine eggs.

The cumulus appears to be critical for fertilization also in the least shrew, Cryptotis parva, in which only cumulus-invested eggs could be penetrated in vitro; its naked eggs are always unfertilized with intact spermatozoa adherent to the zona (Bedford et al., 1977c). Here also, where eggs had already lost the cumulus in a delayed mating situation, the spermatozoa attached to the zona pellucida were intact. Thus, it may prove that regulation of the acrosome reaction in shrews does not involve the zona pellucida. Since epididymal, ejaculated, nor isthmic spermatozoa displayed any affinity for the homologous zona (Bedford et al., 1994; and this study), these observations also imply that the surface of the Suncus spermatozoon, which is differentiated dorso-ventrally (Cooper and Bedford, 1976), may undergo some functional change within the ampulla.

That a cumulus should be able to induce the acrosome reaction is in fact not unusual. Ultrastructurally normal reactions have often been noted within the cumulus, for example in rabbits, in vivo (Bedford, 1968) and in humans, in vitro (Chen and Sathananthan, 1987), and an activity that induces the acrosome reaction has been detected in the hamster cumulus (Boatman and Robins, 1991). In these and other common mammals, however, not only can elements expressed at the zona surface induce the acrosome reaction but, before 
penetration, fertilizing spermatozoa are bound to the zona by the reacted acrosome, which appears as a vesiculated carapace in thin section (Barros et al., 1967). Therefore, a question arises as to how Suncus spermatozoa that lose the acrosome within the cumulus can then bind to the zona pellucida in its absence? For, as was the case for all moving within the cumulus, spermatozoa firmly adhering to unfertilized eggs had no visible remnant of the acrosome. In considering the evident tenacity of their attachment we were reminded, however, that the perforatorium has an unusual 'cox-comb-like' configuration (Mori and Uchida, 1985; Mori et al., 1991; Phillips and Bedford, 1985), the significance of which has been unclear.

In the case of Suncus, it was first suggested that the barbed extensions of its perforatorium may act to stabilise the gigantic acrosome (Phillips and Bedford, 1985), but a similarly barbed if less elaborate perforatorium sits within the unremarkable acrosome in soricine shrews (Mori et al., 1991; Bedford et al., 1997c), and in some megabats (Cummins et al., 1988; T. Mori, unpublished observations). However, in view of the absence of the reacted peri-acrosomal surface on which the zona receptors of the spermatozoa are usually located, it appears that fertilizing spermatozoa of Suncus (and perhaps other species with this type of perforatorium), could use the exposed barbs to attach to the zona surface. Although this could occur in conjunction with receptors present on the inner acrosomal membrane, as suggested in Fig. $5 \mathrm{~b}$ its slightly recurved spikes might simply snag the zona substance, to become anchored in fish-hook fashion by rocking movements of the head brought by the strong one-dimensional beat of the tail. At the same time, it has yet to be explained why other spermatozoa moving in the perizonal space never attach to the fertilized egg. The block to polyspermy that prevents further binding to the zona after fertilization in mice and hamsters, involves subtle modification of zona surface ligands for the reacted acrosome (see Yanagimachi, 1994). Bearing in mind the likely role for the apical barbs exposed on its spermatozoa head, the inability to bind to the activated egg of Suncus may reflect some change in the organization of the zona surface that is visible, and explorations are being conducted with the scanning electron microscope now to examine this possibility.

Compared with the patterns established for the mouse and other advanced mammals, Suncus murinus differs in regard to the form and behaviour of the cumulus oophorus, which seems to induce the acrosome reaction. It differs also, apparently, in the mode of binding of spermatozoa to the zona pellucida which probably involves the barbed perforatorium. The specialised structural character of the acrosome in Suncus (Bedford et al., 1994) raises a further possibility that its reaction also may prove to be distinct in this species. Since the very limited observations on ovarian structure suggest that other insectivores ovulate a similarly compact cumulus, useful perspectives on some of these idiosyncrasies may come not only from investigation of other shrews, but also of moles and hedgehogs.

The work was performed in the Zoological Laboratory, Faculty of Agriculture, Kyushu University. The authors are very grateful to S. Shiraishi for his support. J. M. Bedford was a Special Foreign Visiting Professor under the auspices of the Japanese Ministry of Education.

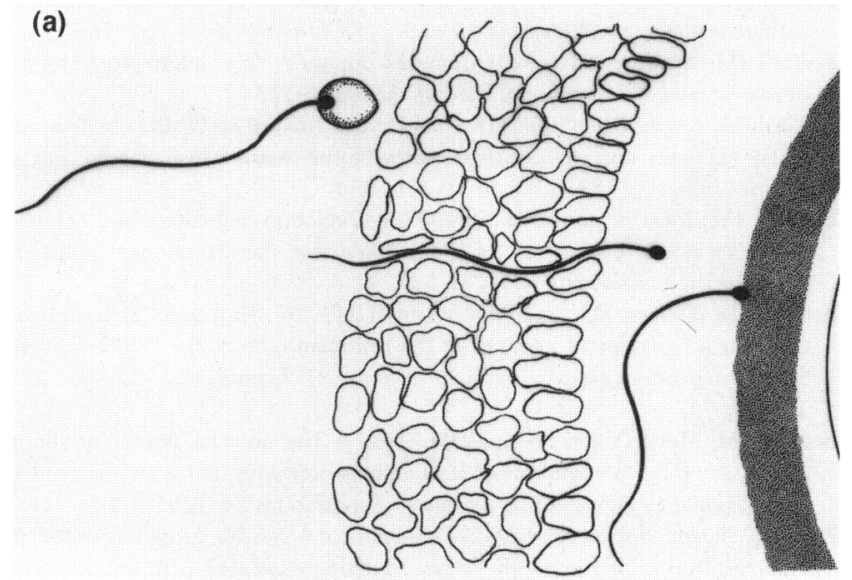

(b)
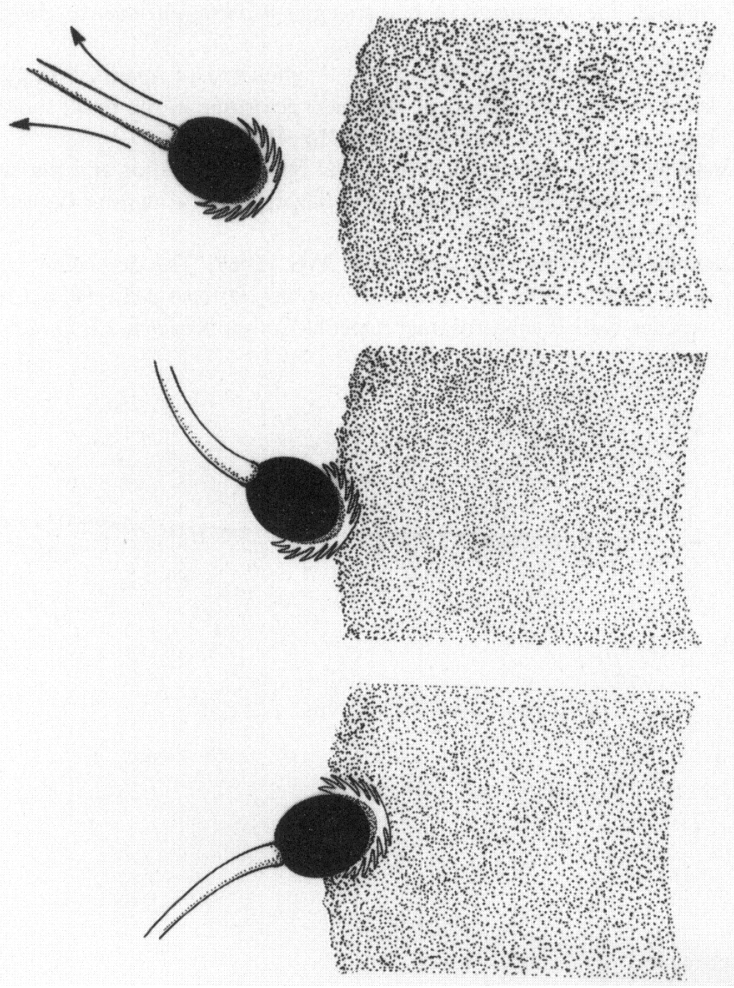

Fig. 5. (a) The apparent sequence in which initially intact spermatozoa of Suncus murinus interact with the cumulus oophorus and discard the acrosome by the time they reach the perizonal space and attach to the zona pellucida. (b) Reacted spermatozoa of Suncus murinus seem likely to attach to the zona pellucida by the exposed barbs of the elaborate perforatorium. After initial involvement with the zona is established on one side, a reverse oscillation of the head brought by a counter beat of the tail - which typically displays a strong lateral planar beat - could serve to ensnare the head within the periphery of the zona.

\section{References}

Barros C, Bedford JM, Franklin LE and Austin CR (1967) Membrane vesiculation as a feature of the mammalian acrosome reaction Journal of Cell Biology $\mathbf{3 4}$ $\mathrm{C} 1-\mathrm{C} 3$

Bedford JM (1968) Ultrastructural changes in the sperm head during fertilisation in the rabbit American Journal of Anatomy 123 329-358 
Bedford JM (1996) What marsupial gametes disclose about gamete function in eutherian mammals Reproduction Fertility and Development 8 569-580

Bedford JM and Kim HH (1993) Cumulus oophorus as a sperm sequestering device Joumal of Experimental Zoology 265 321-328

Bedford JM, Cooper GW, Phillips DM and Dryden GL (1994) Distinctive features of the gametes and reproductive tracts of the Asian Musk Shrew, Suncus murinus. Biology of Reproduction 50 820-834

Bedford JM, Mori T and Oda S (1997a) Ovulation induction and gamete transport in the female tract of the musk shrew, Suncus murinus. Journal of Reproduction and Fertility 101 115-125

Bedford JM, Phillips DM and Mover-Lev H (1997b) The novel spermatozoa crypts and behavior of gametes in the Fallopian tube of the White-toothed Shrew, Crocidura russula monacha Journal of Experimental Zoology 277 262-273

Bedford JM, Mock O and Phillips DM (1997c) The unusual ampullary sperm crypts, and behavior and role of the cumulus oophorus, in the oviduct of the Least Shrew, Cryptotis parva. Biology of Reproduction 56 1255-1267

Boatman DE and Robins RS (1991) Detection of a soluble acrosome-reactioninducing factor, different from serum albumin, associated with the ovulated egg-cumulus complex Molecular Reproduction and Development 30 396-400

Chen C and Sathananthan AH (1986) Early penetration of human spermatozoa through the vestments of human eggs in vitro. Archives of Andrology 16 183-197

Cooper GW and Bedford JM (1976) Asymmetry of spermiation and sperm surface charge patterns over the giant acrosome in the musk shrew, Suncus murinus. Journal of Cell Biology 69 415-428

Cummins JM and Yanagimachi R (1982) Sperm egg ratios and the site of the acrosome reaction during in vitro fertilization in the hamster Gamete Research 5 239-256

Cummins JM, Robson SK and Rouse WG (1987) The acrosome reaction in spermatozoa of the grey-headed flying fox (Pteropus policephalus: Chiroptera) exposes barbed subacrosomal material Gamete Research 21 11-22
Dryden GL (1969) Reproduction in Suncus murinus. Journal of Reproduction and Fertility Supplement 6 377-396

Mori T and Uchida TA (1985) Fine structure of the spermatozoon of the house musk shrew, Suncus murinus In Suncus murinus - Biology of the Laboratory Shrew, pp 335-35I Eds S Oda, J Kitoh, K Ota and G Isomura. Japan Science Societes Press, Tokyo (Japanese with English summary)

Mori T, Arai S, Shiraishi S and Uchida TA (1991) Ultrastructural observations on spermatozoa of the Soricidae, with special attention to a sub-family revision of the Japanese water shrew Chimarrogale himalayica. Journal of the Mammalogical Society of Japan 16 1-12

Mossman H and Duke KL (1973) Comparative Morphology of the Mammalian Ovary University of Wisconsin Press, Madison, Wisconsin

Pearson OP (1944) Reproduction in the shrew (Blarina brevicauda Say) American Journal of Anatomy 75 39-93

Phillips DM and Bedford JM (1985) Unusual features of sperm ultrastructure in the musk shrew, Suncus murinus. Journal of Experimental Zoology 235 $119-126$

Shalgi R and Phillips DM (1988) The motility of rat spermatozoa at the site of fertilization Biology of Reproduction 39 1207-1213

Strauss F (1952) Ripe follicles without antra and fertilization within the follicle: a normal situation in a mammal Anatomical Record 106 251-252

Yanagimachi R (1994) Mammalian fertilization. In The Physiology of Reproducfion (2nd Edn) pp 189-317. Eds E Knobil and JD O'Neill. Raven Press, New York

Yates TL (1984) Insectivores, elephant shrews, tree shrews and dermopterans. In Orders and Families of Recent Mammals of the World, pp 117-144 Eds S Anderson and JK Jones. John Wiley, New York

Zamboni L (1972) Fertilization in the mouse In Biology of Mammalian Fertilization and Implantation, pp 213-262 Eds KS Moghissi and ESE Hafez. Thomas, Springfield. 